\title{
Emphasizing Behavioral Science Awareness with Intelligence Operations in the Information Age As Global Intellectual Challenge
}

\author{
James A Schnell* \\ Ohio University, USA \\ Submission: November 16, 2017; Published: December 07, 2017 \\ *Corresponding author: James A Schnell, Fulbright Scholar Association, Ohio University, USA, Email: james.schnell@fulbrightmail.org
}

\section{Introduction}

The behavioral sciences offer a wide range of perspectives for understanding the world around us. This is true in general terms and in more narrow domains, such as specific focus on intelligence operations conducted by national intelligence agencies. It is clear that what applies on the general level can also have application in some of the more specific areas of social life.

One must merely give due consideration for context and the impact of context as a relevant. Forty years of my life have been spent working on matters in, or associated with, the global intelligence community-most notably issues involving ChinaU.S. relations. This has involved observation of dedicated efforts focusing on large scale operations involving painstaking focus on the most minute of details. Plans developed and executed. Advancements celebrated. Losses mourned. Stalemates endured. Careers, lives and dreams swallowed up with such things. Very much commensurate with a large complex game of chess. Social and behavioral science emphasis has been a significant variable with the aforementioned.

Twenty-five years ago we heralded a new world order, a new age in global relations, offering hope for a post-Cold War era that could reimagine functioning of global intelligence systems. Techniques have been modified, especially in relation to the new communication technologies, but little has changed regarding the vision involved with what is being addressed and how that vision might mature in ways commensurate with our

more interconnected global community, poised to build upon shared understanding and common goals. A vision that allows for assumed commonality rather than assumed adversarial positions.

Instead, we are seemingly still perfecting the art of extending adversarial relations in that our organizational cultures are locked into such frameworks and machinations. Reward systems and ways of functioning-foundations for promotions and career progression-so ingrained that innovative macro-level thinking is looked upon with suspicion. We are left rearranging the deck furniture on the Titanic. Alas, it is being done with precision and vigor. Oblivious to the icebergs that we need to be considering.

Parallels exist with armies who clash on the field of battle, sacrificing lives for days on end to take a "Hamburger Hill," and then-after the hill is taken-are left with no alternative but to abandon it and move on to the next hill to be taken. Only to have to return and re-take the same hill when it is re-occupied by enemy forces. So much lost but, in reality, very little gained-even by the victor in such contests.

We find ourselves at a point in history where we can reconsider such ways of thinking and functioning. Or, rather, the historical trend may simply bypass what we are doing as obsolete and larger social forces will focus on measures that can be more beneficial in moving the ball forward to goals that are truly worthy of our attention and resources. That is, no confrontation will be needed. The public mind will simply look elsewhere for answers to the questions it has. Social science domains will serve as context for this phenomenon.

The Chinese" Belt and Road Initiative"(BRI). Exemplifies a panorama for this new order of thinking. As the world becomes more interconnected we find ourselves encountering a phenomenon that has been historically less common but is becoming more common with increasing frequency. Most namely, that peoples who have rarely been in contact with each other in the past are now dealing with each other on a frequent basis via business, travel, education and popular culture venues.

BRI offers an evolving venue for such interaction. China's president Xi Jinping announced creation of the BRI in 2013. It is intended to reorient relations among China and other countries in the Eurasian community. There are two aspects of BRI: an overland "belt" connecting China with Central Asia, Russia, South 
Asia, and Europe and a maritime "road" linking Chinese ports with those in Southeast Asia, South Asia, Africa, the Middle East, and Europe.

A key part of BRI is that it will be an egalitarian venture among the 68 countries that will be connected via the "belt and road." It will stress common interests rather than hegemonic intentions based on control and cultural imperialism. Trust, mutual benefit and shared governance will be key elements within this process. There will certainly be disagreements confronted but, with this type of egalitarian foundation, BRI will perpetuate an institutional culture that promotes fairness and consensus.

BRI will evolve in this manner, not so much because it is the politically correct manner to proceed, but because it will be the most expedient way to progress. Such an internationally oriented venture, with so many varied cultural constituencies involved, will not be able to exist with hegemonic practices by any major national power. Offering a carrot, rather than threatening with a stick, will be the order of the day.

This has potential of providing a model for the rest of the global social order that can be incorporated into institutional structures. The international intelligence community is one such institutional structure ripe for reorienting. The flow of information on the internet has made intelligence operations objectives from the past, that sought to uncover such information, obsolete. What took months \& years of collection \& analysis can now often be deduced in a matter of minutes via the internet. This is not only impacting how issues can be addressed but redefining the relevance of such issues.

For instance, the objective of establishing "cover" (false identity)-as a social science framework-in some settings has been a factor for operatives in the global intelligence community for well over a thousand years. In modern times this could simply be done by developing a plausible identity, memorizing it, printing some business cards \& related false documents and presenting yourself with confidence regarding who you were pretending to be. The evolution of Google, and related capabilities, has practically rendered such techniques useless in that a false identity can be unmasked without much effort. Which ultimately calls into question the relevancy of such "cover" objectives in the first place.

The internet has opened an entire panacea for cyber oriented intelligence operations. Hence, the U.S. Air Force has stood up an entire cyber command. This will not only offer new means for addressing issues of interest. It will make many of those issues of interest irrelevant. The relatively free exchange of information via the internet is redefining the social order. This is not happening all at once but, rather, such changes are progressing on varied levels with resounding impact. Ultimately, we will find that much of what the global intelligence community does will become obsolete. Huge savings will be realized with the slashing of intelligence operations budgets-freeing up resources for newer tangential issues evolving on the horizon.

The social and behavioral sciences will be part of this evolution. Related impacts can be recognized with journalism, specifically broadcast journalism, and resulting influence on the intelligence community. When Saddam Hussein invaded Kuwait, and we had the resulting Desert Shield/Desert Storm operations in the early 1990s, policy makers typically followed events more via CNN reporting rather than intelligence reporting. The CNN reporting was often live and prompted immediate response from global players. It was the landscape that the public was watching. It could not be ignored, even if it was inaccurate at times, in that it was accurate often enough to be consistently accepted as truth-or close to the truth.

For the aforenoted reasons, it is worth acknowledging that even the intelligence community started following CNN reporting. I was working in the "Watch Center" (intelligence unit) of the National Air Intelligence Center at Wright-Patterson Air Force Base on the night Saddam Hussein invaded Kuwait. Within hours of the event, a television was rolled into the "Watch Center" so we could follow developments on CNN. That television was on, with continual CNN reporting, 24/7 (24 hours a day, seven days a week). Within a month a television was permanently hung from the ceiling for ongoing viewing that has continued from well after Desert Storm ended into the range of events since then. Such journalistic news reporting has been primary for the intelligence community since that point in time.

Similarly, the internet and related new communication technologies are redefining the intelligence operations landscape within the larger realm of social science frameworks. Those in the intelligence community can reform in relation to the changes or be rendered irrelevant by them. The Chinese BRI intentions, if legitimate and sincerely embraced, offer global superpower intelligence agencies the opportunity to be contributors toward this reshaping of global relations rather than existence as outdated challenges to it. The social and behavioral sciences will be part of this process. 


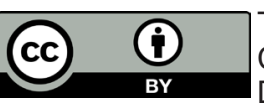

This work is licensed under Creative Commons Attribution 4.0 Licens

DOI: 10.19080/GJIDD.2017.04.555628
Your next submission with Juniper Publishers will reach you the below assets

- Quality Editorial service

- Swift Peer Review

- Reprints availability

- E-prints Service

- Manuscript Podcast for convenient understanding

- Global attainment for your research

- Manuscript accessibility in different formats ( Pdf, E-pub, Full Text, Audio)

- Unceasing customer service

Track the below URL for one-step submission https://juniperpublishers.com/online-submission.php 